\title{
A GESTÃO DO DESIGN COMO DIFERENCIAL DE QUALIDADE NAS INDÚSTRIAS MOVELEIRAS DO ALTO URUGUAI GAÚCHO
}

\author{
José Paulo Medeiros da Silva \\ Universidade Regional do Noroeste do Estado do Rio Grande do Sul \\ jp_designer@yahoo.com.br
}

\author{
Alberto Souza Schmidt \\ Universidade Federal de Santa Maria \\ albertoschmidt56@gmail.com
}

Resumo: O desenvolvimento da inovação tecnológica, impulsionado pelo processo de internacionalização das empresas vêm desencadeando importantes mudanças no desempenho da economia, na competição e revolução do conhecimento. Por julgar de essencial importância compreender a função e atribuição que o design desempenha no setor moveleiro, o foco deste estudo consiste identificar culturalmente como as indústrias moveleiras da região do Alto Uruguai/RS atuam em relação à percepção design, e propor ações para a implantação da Gestão de Design, visando à efetivação do design e melhoria da qualidade das empresas. O trabalho contou com levantamento bibliográfico e documental, entrevistas estruturadas e semi-estruturadas e pesquisa de campo. A pesquisa apontou que a maioria das empresas demonstra compreender a importância do design para o desenvolvimento de seus produtos, porém, são poucas as que investem no sentido de sua efetivação. Logo, a gestão de design, sendo um meio de integração e interação de diferentes áreas, pode reverter este quadro promovendo o diferencial competitivo tão necessário para sua sobrevivência e o desenvolvimento econômico da região na qual está inserida.

Palavras-chave: Gestão do Design, Qualidade, Indústrias Moveleiras, Alto Uruguai/RS.

Abstract: The development of technological innovation, driven by the internationalization process of companies, products and markets, is triggering major changes in economic performance, competition, in deregulation and in the revolution of knowledge. Realizing of essential importance to understand what function and role design plays in the national furniture industry and to understand how its products are developed, the focus of this study is to identify culturally how the furniture industry in Alto Uruguai/RS operates in relation to the design and propose 
actions to implement the Design Management, aiming to the effectuation of the design and improvement of quality in the companies. . The work was supported by bibliographic and documental resources, structured and semi-structured interviews and also by fieldwork. The research showed that the vast majority of companies demonstrate to understand the importance of design for the development of its products; however, there are few that invest in its accomplishment. Therefore, the design management, being a means of integration and interaction of different areas, can reverse this situation by promoting in the companies the competitive differential that is so necessary for their survival, such as the economic development in the region in which it operates.

Keywords: Design Management, Quality, Furniture Industries, Alto Uruguai/RS.

\section{INTRODUÇÃO}

O setor moveleiro nacional está passando por inúmeras transformações, sobretudo no que diz respeito à implantação de novas tecnologias para produção e metodologias de trabalho, principalmente, para desenvolvimento de novos produtos. Nesta primeira década do século XXI, as organizações depararam-se com uma nova realidade, principalmente devido à globalização da economia, onde a possibilidade de crescimento em quantidade e qualidade tornou-se mais tangível, além de sentir uma necessidade de fortalecimento de sua capacidade produtiva, devido a forte concorrência de produtos estrangeiros. Isso impôs uma necessidade de reestruturação e preparação para as novas demandas, visando não apenas a melhoria da qualidade dos seus produtos, mas também a sobrevivência das mesmas no mercado.

Para Quarante (1992), as empresas que utilizam seu empenho significativo em relação à qualidade, possuem maior possibilidade de sucesso com a aplicação do design, pois experimentaram um processo de mudança de cultura, e assim obtêm êxito, dispondo de maior habilidade para que este desenvolva toda a sua potenciabilidade. Cases de empresas bem sucedidas, desfrutam de credibilidade e fidelidade por parte dos consumidores, utilizando o design como ferramenta eficiente para criar e implantar cultura empresarial, que compreende o produto final como uma manifestação integrada de todas as etapas que correspondem ao desenvolvimento do produto, refletindo a imagem da empresa através desse.

Por julgar de essencial importância compreender qual a função e atribuição que o design desempenha no setor moveleiro nacional e entender como são desenvolvidos seus produtos este trabalho tem como objetivo identificar como as indústrias do alto Uruguai Gaúcho estão organizadas em relação aos aspectos voltados ao design e propor ações para a implantação da Gestão de Design.

\section{DESENVOLVIMENTO}

Para realização do estudo estabeleceu-se uma visão geral a respeito das indústrias moveleiras do Alto Uruguai/RS, enfatizando a utilização do design no processo de Desenvolvimento de Novos Produtos (DNP). O trabalho contou com levantamento bibliográfico e documental, entrevistas estruturada e semi-estruturadas 
e pesquisa de campo. O método escolhido para a elaboração deste trabalho foi o estudo descritivo e a abordagem do problema ocorreu pela forma de uma pesquisa qualitativa, que foi realizada através do estudo de campo com proprietários e gerentes de micro, pequenas e médias empresas selecionadas e, também, com funcionários responsáveis pelo processo de DNP. Para composição da amostra foi utilizado o método não probabilístico, no qual selecionou-se uma amostra por conveniência. Optou-se pelas empresas situadas no município de Erechim como foco da pesquisa devido à sua importância e representatividade na região do Alto Uruguai/RS. Assim, definiu-se o universo da pesquisa em 20 (vinte) empresas. Das 16 empresas que retornaram o questionário, $70 \%$ são micro empresas, refletindo o panorama do setor moveleiro nacional, que se caracteriza pelo elevado número de micro e pequenas empresas e grande absorção de mão de obra. Com relação ao tipo de produção, 07 (sete) empresas trabalham com móveis seriados e 09 (nove) com móveis sob medida, sendo que 01 (uma) destas também comercializa móveis seriados de outros fabricantes.

\subsection{A qualidade}

O termo qualidade possui diferentes significados, dependendo não só do enfoque teórico-metodológico como também do período histórico em que está inserido e do processo produtivo. Embora o termo qualidade tenha permanecido ao longo do tempo sempre associado à ideia de excelência ou superioridade de um produto ou serviço, o conceito foi aos poucos agregando outros valores, sendo o primeiro deles o valor de mercado. De acordo com Godoy et al. (2009):

\footnotetext{
"Cada vez mais a qualidade está sendo considerada como fator decisivo para a melhoria não só do desempenho como também da sobrevivência da própria organização no mercado. Em busca da qualidade total, as organizações buscam aperfeiçoar processos, produtos ou serviços e, acima de tudo, satisfazer seus clientes".
}

A partir da década de 50, surgiu a preocupação com a gestão da qualidade, que trouxe uma nova filosofia gerencial com base no desenvolvimento e na aplicação de conceitos, métodos e técnicas adequados a uma nova realidade. A Era da Qualidade Total marcou o deslocamento da análise do produto ou serviço para a concepção de um sistema da qualidade. A qualidade deixou de ser um aspecto do produto e responsabilidade apenas de departamento específico, e passou a ser um problema da empresa, abrangendo, como tal, todos os aspectos de sua operação.

Assim, a qualidade tem como função não apenas identificar novas oportunidades para o desenvolvimento de processos, produtos e mercados, mas também influenciar e alterar as exigências de consumo nos mercados existentes. Portanto, a atual definição incorpora noções de melhor preço, ausência de defeitos, obediência ao projeto, adequação ao uso e satisfação do cliente por meio de melhoria contínua nos produtos e serviços oferecidos. Pode-se afirmar que este processo de melhoria contínua também envolve a integração do design na gestão da qualidade em organizações.

\subsection{A gestão do design}

Acredita-se que a gestão do design surgiu em 1907, com o arquiteto Peter Behrens, que comandava (como diretor artístico) a Allgemeinen Elektricitats 
Gesellschaft (AEG), desenhando todos os seus produtos, fábrica, habitações para funcionários, identidade e desenhos publicitários. O enfoque da gestão de design ocorre na qualidade, que é uma porta de entrada do designer nas organizações, devido às suas habilidades específicas (criatividade, iniciativa, atenção ao detalhe, atenção ao cliente). Por isso, Santos (2000) relaciona a evolução do design com a evolução da qualidade e chega ao design estratégico, a que chama de "Quarta Era" (Figura 1).

Pode-se descrever a gestão do design como a atividade macro das estratégias que designers (ou grupos interdisciplinares, com poder decisório em que o design esteja envolvido) estruturam para moldar um perfil da empresa com base nos produtos desenvolvidos e/ou na identidade visual que a representa. Para Wolf (1998), esta gestão possui a função de "planejar e coordenar as estratégias correspondentes aos objetivos e valores da empresa, motivar os empregados e controlar os trabalhos, assegurando com que cumpram os objetivos, com os prazos e custos planejados". Assim, a importância desta gestão para o desenvolvimento do país como processo e ferramenta estratégica, está na contribuição para a materialização de produtos e/ou de seus processos, incorporando os objetivos da empresa, tornando-se, desta forma, uma atividade necessária às organizações.

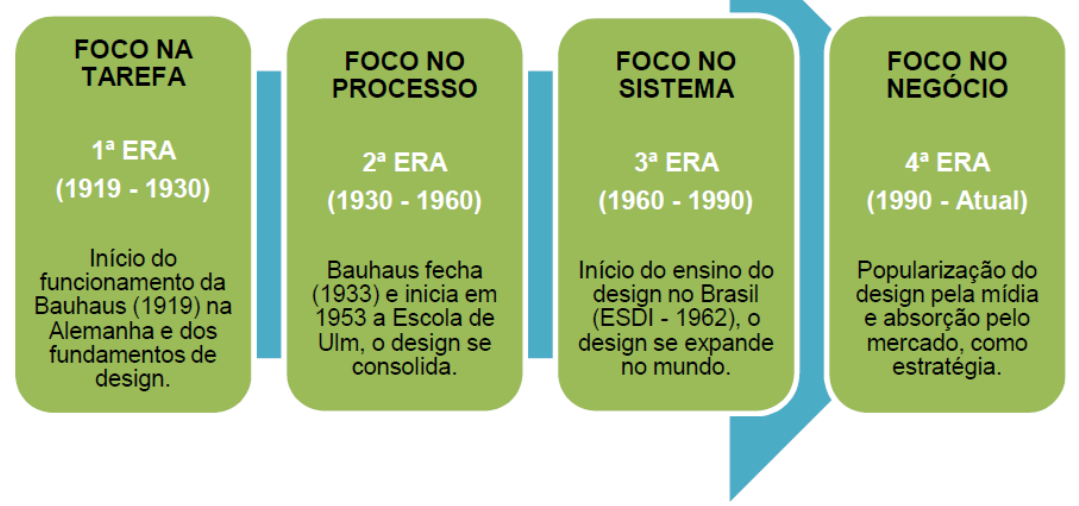

Figura 1 - Linha de tempo do design.

Fonte: Santos, 2000.

\subsection{0 design e a gestão da qualidade}

Segundo Baxter (2003) o processo de DNP é uma atividade complexa, pois envolve diversos interesses e habilidades, como os dos consumidores que desejam novidades, melhores produtos a preços razoáveis; os vendedores que desejam diferenciações e vantagens competitivas; os engenheiros de produção que desejam simplicidade na fabricação e facilidade de montagem; os empresários que querem poucos investimentos e retorno rápido do capital; e por fim os interesses do próprio designer que busca a experimentação de novos materiais, processos e soluções formais.

Com relação à qualidade em produtos, esta não se refere somente à parte visível ou de acabamento. Refere-se antes, a todo um processo que culmina em um produto compatível e adequado às expectativas de quem vai usá-lo, ou seja, desenvolvimento do produto significa fornecer características do produto que respondam às necessidades e expectativas do cliente (Figura 2). Cada cliente deve ser tratado como único e exige, também, uma característica de produto única. Para isso, 
cada uma dessas características deve obedecer aos seguintes critérios: atender às necessidades do cliente, às necessidades da empresa (como fornecedores), à concorrência e otimizar os custos combinados da empresa e dos clientes.

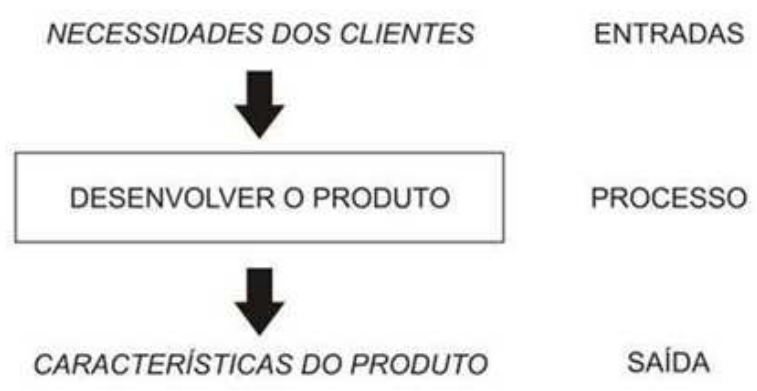

Figura 2 - Diagrama de entrada e saída para desenvolvimento do produto.

Fonte: Juran (1995).

Logo, a gestão da qualidade pode acontecer em produtos, processos e serviços e engloba uma série de procedimentos que visam à melhoria contínua. Este modelo administrativo foi concebido pelos americanos Deming e Juran, que ajudaram na construção da indústria japonesa nos anos 50. Mais tarde, os empresários americanos, intrigados com o desenvolvimento e a eficiência da indústria japonesa percorreram o caminho inverso dos japoneses, que anos antes buscavam nos Estados Unidos e Europa produtos que consideravam de grande qualidade e importância para serem produzidos.

No entanto, a gestão da qualidade ou qualidade total vem sendo introduzida nas empresas ocidentais e, em especial, nas brasileiras, sem que estes princípios sejam adaptados a nossa realidade. Algumas empresas podem não obter os resultados esperados, pois a tentativa de implantação dá-se verticalmente, de cima para baixo, sem o envolvimento necessário de todas as áreas da empresa, sem a compreensão plena do verdadeiro significado da gestão da qualidade e, em muitas situações, dentro de um enfoque de adoção de tecnologias desenvolvidas em outros países, sem observância das questões culturais locais.

Pode-se afirmar que "a rápida recuperação da indústria japonesa trouxe uma nova perspectiva ao design e aos designers, graças à implementação dos processos de gestão da qualidade, integrando o design ao planejamento estratégico das empresas" (NASCIMENTO, 2001). Esta afirmação conduz a uma nova visão do que seja design; integra o design a outras disciplinas e o incorpora ao mundo da empresa. $\mathrm{O}$ design deixa de ser um ato criativo individual, para fazer parte e circunscrever-se num contexto econômico do qual não se pode mais prescindir.

\subsection{0 design na indústria moveleira}

A indústria brasileira de móveis é muito fragmentada e caracteriza-se principalmente por dois aspectos: elevado número de micro e pequenas empresas e grande absorção de mão de obra (ABIMÓVEL, 2011). A principal fonte do design, adotada pela grande maioria dessas empresas, e, também por algumas grandes empresas, é o que se pode chamar de "projeto híbrido", que consiste na unificação de diversos modelos em um único novo modelo, tendo com fontes de informação e inspiração os modelos observados em revistas e catálogos de empresas concorrentes, 
feiras nacionais e internacionais. Em resumo, as empresas procuram observar as principais tendências de mercado e elaborar um novo modelo que, na verdade, é a cópia de diversos modelos em um único produto.

Outra fonte de design, em particular para as grandes empresas, é o desenvolvimento de projetos próprios. Algumas adotam esta estratégia de forma ainda bastante rudimentar, por meio do processo de tentativa e erro. Outras indústrias desenvolvem projetos próprios de maneira mais eficiente, apoiadas no trabalho direto de especialistas da empresa, além da contratação dos serviços de designers ou escritórios de design. Cabe destacar que, em muitos casos, o desenvolvimento de projetos próprios é adotado por fabricantes que anteriormente utilizavam o projeto híbrido, sendo assim uma estratégia de construção de vantagens competitivas por parte delas.

Uma terceira fonte do design na indústria de móveis é a compra e adaptação de projetos estrangeiros. Esta estratégia de obtenção é adotada particularmente pelas grandes empresas do segmento de móveis de escritório, assim como pela grande maioria das exportadoras de móveis.

Do ponto de vista da formação de uma cultura industrial no setor, verificou-se, portanto uma "descontinuidade" histórica que nos remete a difíceis desafios para o avanço competitivo do setor (GORINI, 1998). Portanto, essa formação desigual da cultura industrial do setor moveleiro deve ser considerada na elaboração das estratégias de mercado, de modo a possibilitar uma complementaridade interpolo. Conforme destacado pelo diretor de uma empresa do polo de Bento Gonçalves (RS): "a concorrência do nosso setor moveleiro atual é com o móvel estrangeiro, não mais entre empresários nacionais".

\section{CONCLUSÃO}

\subsection{Resultados obtidos}

Referente ao tipo de mobiliário (em relação ao volume produzido), $40 \%$ são móveis residenciais, $31 \%$ móveis para escritório e $29 \%$ móveis para uso público, como móveis escolares, para hospitais, consultórios, hotelaria, auditórios, igrejas, parques e clubes (Figura 3). O material mais utilizado é a madeira e/ou derivados, seguido pelo metal em segundo e o plástico em terceiro.

Tipo de mobiliário

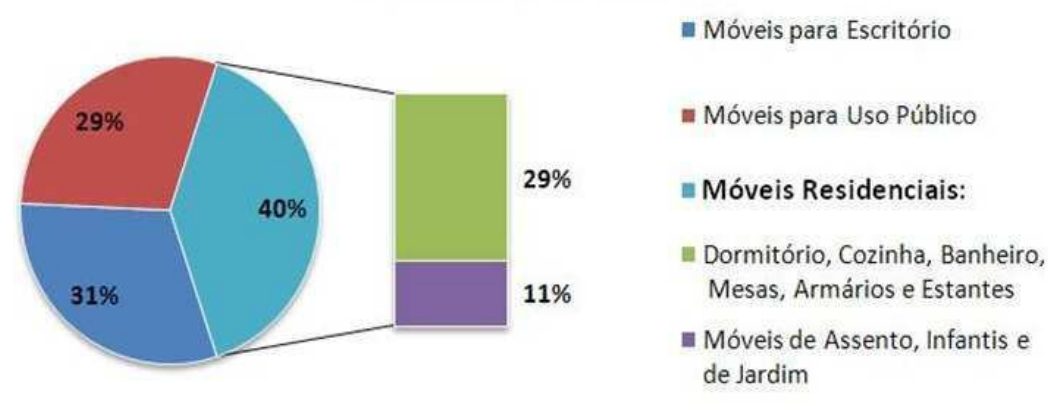

Figura 3 - Tipo de mobiliário.

Fonte: Elaborado pelo autor, com base na pesquisa realizada. 
Quanto ao comportamento das empresas em relação ao produto, solicitou-se que as empresas pesquisadas indicassem três fatores (na visão da empresa), por ordem de importância, que fazem o sucesso do seu produto; foram apontados: durabilidade, em primeiro; design, em segundo; e conforto, em terceiro (Figura 4).

\section{Fatores de sucesso do seu produto}
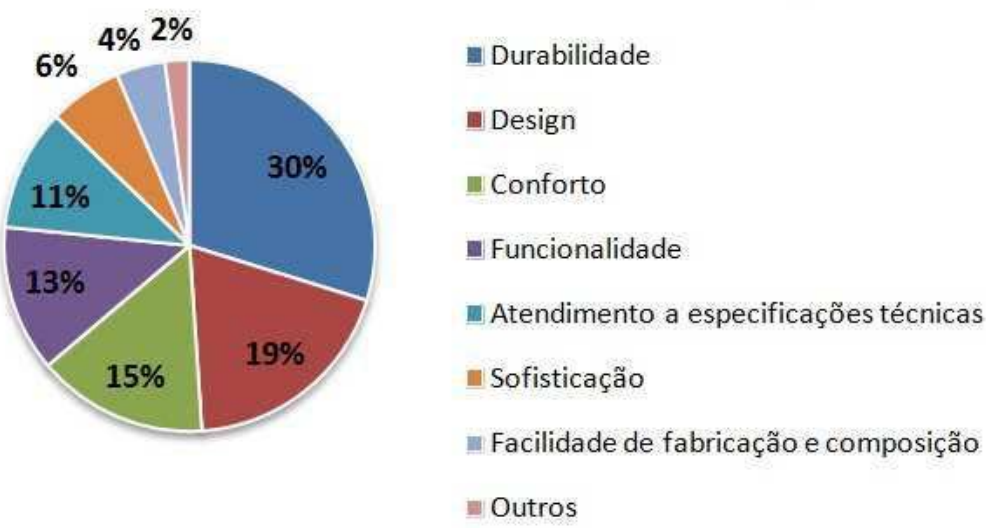

Figura 4 - Fatores de sucesso do seu produto.

Fonte: Elaborado pelo autor, com base na pesquisa realizada.

Quanto à comercialização dos seus produtos, as principais formas citadas foram: diretamente na empresa e/ou pequenos varejistas, e lojas próprias. A pesquisa mostrou que os três fatores de sucesso, por ordem de importância, na comercialização dos produtos das empresas pesquisadas são: marca do produto e/ou tradição da empresa, e prazo ou confiabilidade nos prazos, em primeiro; preço do produto e estilo/desenho, em segundo; e serviços pós-venda/assistência ao consumidor, em terceiro (Figura 5).

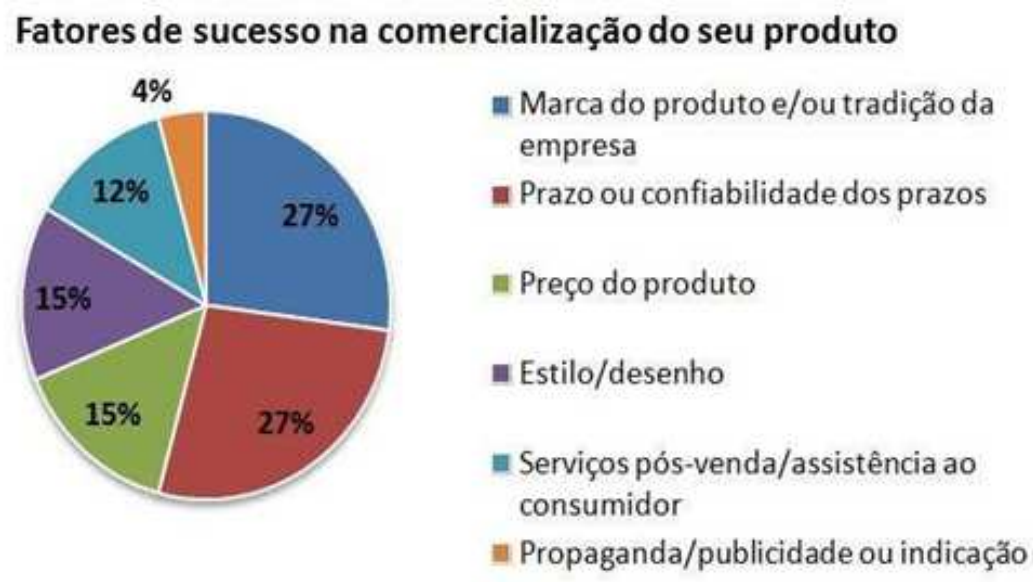

Figura 5 - Fatores de sucesso na comercialização do seu produto.

Fonte: Elaborado pelo autor, com base na pesquisa realizada.

Quanto ao design, a grande maioria afirmou desenvolver internamente e/ou possuir um especialista em design. Das empresas pesquisadas, 11 (onze) afirmaram possuir pessoal especializado, sendo que o número de pessoas envolvidas com design varia de 01 (uma) a 04 (quatro) pessoas. Convém destacar que apenas 03 (três) empresas possuem pessoas com formação específica em design, na maioria dos casos, os próprios gestores são os responsáveis. Também são realizadas parcerias com 
arquitetos, que prestam assessoria no desenvolvimento ou trazem pedidos de clientes para orçamento e/ou produção.

Inquiridas sobre a realização de investimentos em design nos últimos três anos, $50 \%$ das empresas afirmaram terem realizado investimentos. A Figura 6 apresenta em que tipo de atividade esses investimentos foram aplicados. Com relação a quem mais exige da empresa melhorias em design, 14 (quatorze) empresas responderam os usuários finais. Também foram citados os concorrentes e os varejistas.

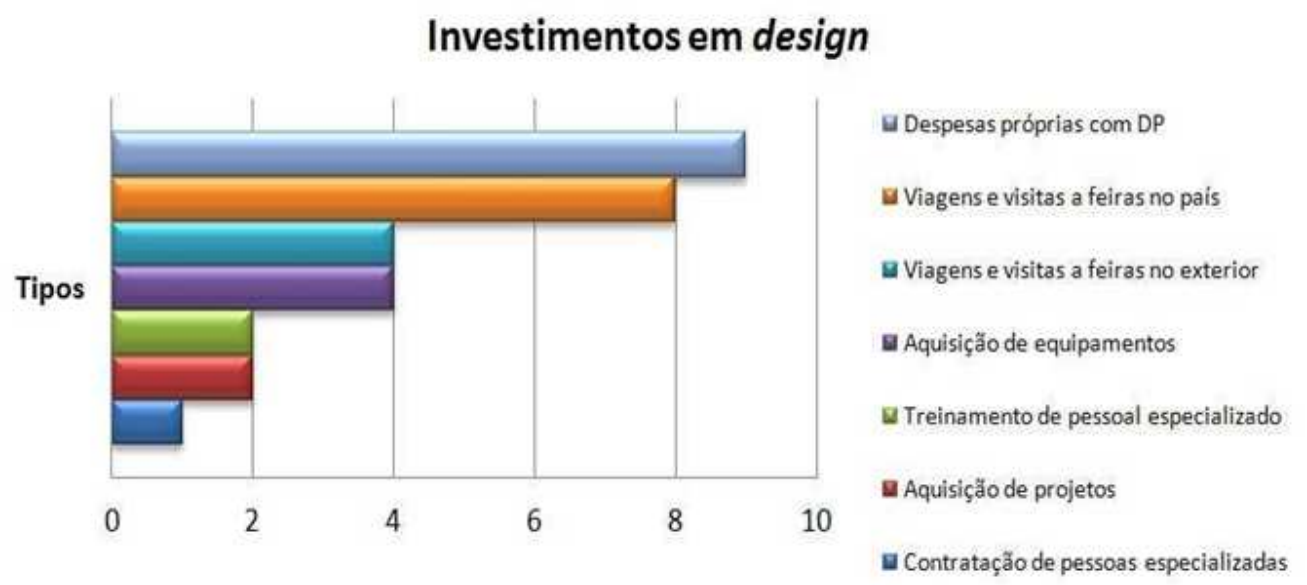

Figura 6 - Investimentos em design.

Fonte: Elaborado pelo autor, com base na pesquisa realizada.

Solicitou-se as empresas pesquisadas para indicar duas iniciativas, por ordem de importância, que consideram mais adequadas para a promoção do design na sua região, as ações mais citadas foram: criação de centros cooperativos, em primeiro; e apoio à formação de escritório de design e escolas técnicas, em segundo (Figura 7). Isto aponta, primeiramente, uma necessidade de melhoria na assistência prestada pelas entidades promotoras, visando à consolidação do design nas empresas; e, em segundo, a ausência de profissionais capacitados para atuarem no setor, onde as atuais necessidades são supridas por profissionais de áreas diversas ou pelos próprios gestores, como relatado anteriormente.

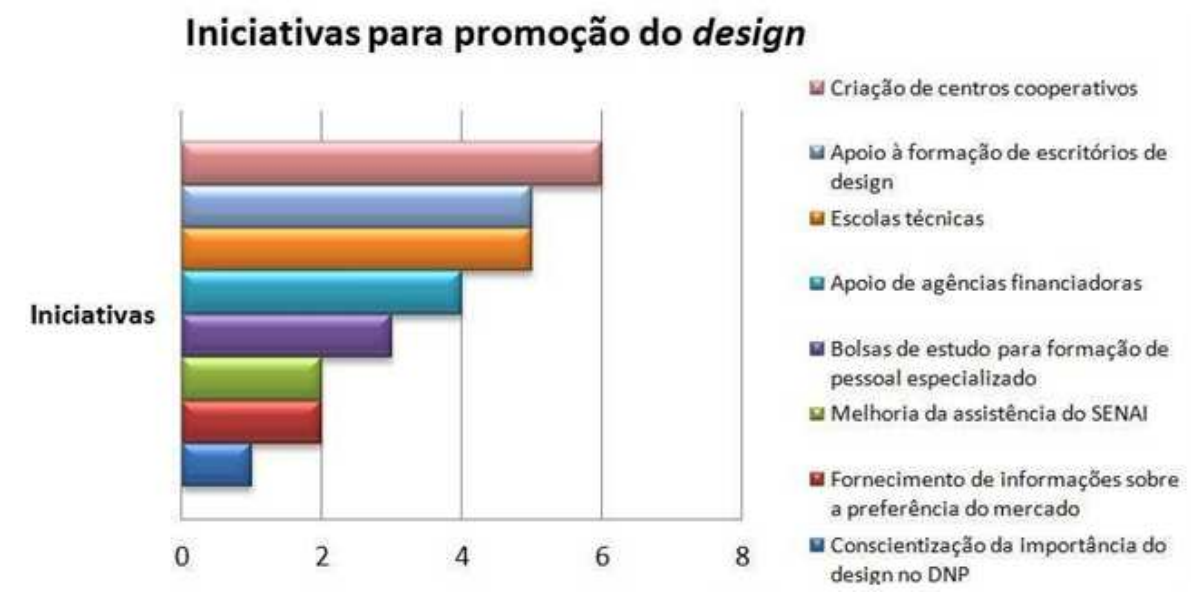

Figura 7 - Iniciativas para a promoção do design.

Fonte: Elaborado pelo autor, com base na pesquisa realizada. 
Quanto ao entendimento por design, a grande maioria das empresas demonstra compreender a importância do mesmo para o desenvolvimento de seus produtos. Segundo o proprietário de uma micro empresa pesquisada, "o design é toda a característica de um produto, tanto no seu material de confecção como na funcionalidade, ou seja, é um conceito fundamental para diferenciação do mesmo frente à concorrência". O gestor de outra empresa complementa: "o design é a capacidade de desenvolver novos produtos que agradem o consumidor de maneira econômica e inovadora, respeitando o meio ambiente e observando o processo produtivo".

Destaca-se que apenas uma das empresas pesquisadas possui um setor específico de design, o qual foram relatados inúmeros investimentos visando o desenvolvimento de novos produtos. Segundo o gerente do setor, "a atuação do design está ligada desde a conceituação até a fabricação do produto e a empresa incentiva que as ações sejam tomadas nesse sentido. Embora a cultura do design e desenvolvimento de produtos ainda não esteja disseminada em todos os processos da empresa, a mesma se mostra ciente da importância e acredita nas ações promovidas por especialistas da área".

No entanto, algumas empresas ainda relacionam o design apenas ao desenho ou estilo do produto. Segundo o designer de uma média empresa pesquisada, "o design ainda não é visto como uma atividade multidisciplinar, que engloba planejamento e integração de diversas áreas, sendo parte de um macro ambiente. É necessário conscientizar os empresários da exigência do mercado por melhores produtos, produtos mais bem pensados, e a importância de ter alguém dentro da empresa pensando nisso".

Convém relatar que apenas em 02 (duas) empresas, o design foi relacionado ao planejamento estratégico. Segundo o proprietário de uma delas, "o design está ligado a todo processo de reestruturação da empresa, através de soluções inteligentes que a posicionam em determinado nicho de mercado, sempre visando à funcionalidade, a qualidade, os custos, a ergonomia e a estética do produto". Para a projetista da outra empresa, "o design é um fator de grande importância para fortalecer a imagem da empresa no mercado, acompanhando as tendências, mas sem perder o foco na necessidade e funcionalidade".

Em relação às principais dificuldades encontradas para a introdução do design dentro da empresa, a grande maioria afirmou que o custo para contratação e/ou manutenção de profissionais da área e, também, a ausência de profissionais com capacitação específica para trabalhar no setor moveleiro, são os principais fatores. Também foram citados: carência de cursos de capacitação e/ou programas de incentivo (tanto de apoio ao design como financeiro), acomodação e/ou falta de entendimento dos gestores e indisponibilidade de recursos financeiros para investimento na área (equipamentos, softwares, P\&D etc.).

Este resultado aponta uma divergência entre o que é compreendido e o que é realizado na prática com relação ao design nas empresas. Segundo o gestor de uma micro empresa pesquisada, "apesar de sabermos da importância do design, ele não é uma necessidade prioritária para nossa empresa, por isso, acabamos terceirizando esta área através de parcerias". Conforme alguns gestores, este tipo de prática é comum 
perante as atuais dificuldades de investimento, mas isso não significa que os mesmos estejam satisfeitos com o resultado desta parceria. Para o proprietário de uma micro empresa, este tipo de associação, além de aumentar o custo final do produto para o cliente, também causa inúmeras dificuldades técnicas para o processo produtivo, devido a falta de conhecimento específico da área e dos padrões adotados pela empresa.

Para o designer de uma média empresa pesquisada, a grande dificuldade para a introdução do design está na mudança de algumas rotinas já pré-estabelecidas e que, bem ou mal, deram certo até o momento. Para ele, "são necessárias algumas experiências para conseguir se definir os limites entre uma atividade e outra, e estabelecer a importância de todas para a saúde da empresa". Além disso, há certa dificuldade em justificar investimentos em design e $P \& D$, pois não se encontram históricos confiáveis de projetos anteriores para comparação ou proposição de metodologias diferentes das que estão sendo utilizadas.

A partir destas informações, foram propostas ações para a implantação da gestão de design nas indústrias moveleiras da região do Alto Uruguai/RS. A implementação da gestão de design nas empresas, de acordo com os resultados da pesquisa, deve iniciar com a presença de um especialista em design (designer ou não), que após avaliar a empresa e sua realidade econômica, estabelecerá uma estratégia compatível com o porte da empresa, levando-se em consideração o grau de inserção atual do design na mesma. Ressalta-se que a iniciativa deve partir das empresas, mas algumas oportunidades podem e devem ser difundidas por outros meios, como entidades promotoras e assistenciais, instituições de ensino, profissionais da área, entre outros. São elas:

I - Estabelecer uma identidade que fortaleça a imagem da empresa e a essência dos seus produtos frente ao cliente. Conforme a pesquisa, a marca e/ou tradição da empresa é um dos fatores de sucesso na comercialização dos seus produtos. Porém, algumas empresas trabalham com diversos tipos de produtos, chegando, inclusive, a comercializar produtos de terceiros. Isto reflete uma falta de foco e desvalorização do produto, onde a quantidade de opções, nem sempre é garantia de qualidade;

II - Destinar o capital disponível no desenvolvimento de novos produtos que promovam a continuidade da produção, mesmo que em pequena escala, evitando assim a dependência de projetos executivos, que muitas vezes não são constantes. $\mathrm{Na}$ verdade, as empresas não devem perder sua capacidade de personalização e adaptação frente às necessidades do cliente, mas buscar uma melhor produtividade, visando o planejamento e padronização do processo produtivo;

III - Os métodos de produção por meio da gestão do design devem ser relativamente simples, de modo que a nível operacional, a demanda de grandes qualificações seja minimizada, não apenas no processo produtivo, mas também pela introdução de novas metodologias, que facilitem e integrem o processo de DNP com os outros setores da empresa;

IV - Utilizar os programas de incentivo ao design, como o Programa Brasileiro de Design, para a busca de informações e referências pertinentes à área; e cobrar das entidades assistenciais, como SEBRAE e SENAI, que desenvolvam e estimulem atividades que contribuam para efetivação do design. Na verdade, as empresas 
carecem de exemplos práticos que orientem a inserção do design, pois a assistência realizada pelas entidades promotoras, na visão dos gestores, é considerada deficiente ou de caráter superficial;

V - Estabelecer parcerias com profissionais da área e incentivar a formação de centros ou núcleos de design na região, de forma a estabelecer redes de cooperação;

VI - Promover a interação entre a empresa e as instituições de ensino, incentivando a capacitação dos funcionários e, também, a criação de programas de estágio para estudantes da área. Como foi relatado anteriormente, a melhor maneira de fomentar o design é através da introdução de profissionais da área, estimulando a troca de informações e a multidisciplinaridade inerente à função;

VII - Participar e incentivar a realização de eventos regionais e nacionais (dependendo do porte da empresa) que divulguem a marca e o produto, colaborando, também, para troca de informações e necessidades entre as empresas;

VIII - Conscientizar os gestores que o design é um investimento em longo prazo, sendo uma necessidade fundamental para competitividade e planejamento estratégico da empresa, situando-a no mercado e agregando valor ao produto;

VIX - Elaborar e facilitar o acesso a manuais informativos, que abordem, entre outros temas, as tendências de mercado, os novos materiais e as particularidades do setor nas regiões.

\subsection{Considerações finais}

Assim como no passado, não houve nenhuma época da civilização humana que surgisse, sem uma fase inicial em que ocorresse uma completa renovação dos valores. Da mesma forma, inserir o design nas indústrias moveleiras é uma renovação de valores e, principalmente, uma renovação cultural. Portanto, acredita-se que o objetivo deste trabalho foi atingido, na medida em que o mesmo identificou como as indústrias do alto Uruguai Gaúcho estão organizadas em relação aos aspectos Gestão do Design e, ainda, foram propostas as ações que visam à efetivação do design e melhoria da qualidade das empresas como um todo, mas é apenas um primeiro passo, já que o design ainda carece de tempo e, principalmente, educação para sua consolidação. Assim, o papel da gestão de design, neste setor, é capacitar e preparar os profissionais envolvidos, além de potencializar as tecnologias disponíveis para o desenvolvimento de novos produtos, na operacionalização e organização das empresas e, principalmente, buscar a excelência na prestação de serviços.

\section{REFERÊNCIAS}

ABIMÓVEL. Associação Brasileira das Indústrias do Moveleiro. http://www.abimovel.com/. Acesso em março de 2011.

BANK, J. The essence of total quality management. New York: Prentice Hall International Edition, 1992.

BAXTER, M. Projeto de Produto: guia prático para o design de novos produtos. 2. ed. São Paulo: Edgard Blücher, 2003. 
BERNARDI, R. Caminhos do III Milênio - Cenários de Evolução. Curitiba: SENAI/CETEMO-RS, 2001.

BRASIL, L.; RIITTO, A. C. A. In: CONGRESSO Brasileiro de Pesquisa e Design P\&D. Design e gestão nas organizações. Anais do IV Congresso Brasileiro de Pesquisa e Design P\&D. Novo Hamburgo, 2000.

DZIOBCZENSKIA, P. R. N.; LACERDA, R.G.; SEREFIN, M.T.; BATISTA, V.J. Inovação Através do Design: Princípios Sistêmicos do Pensamento Projetual. Revista Design \& Tecnologia, Porto Alegre, V. 3, 2011.

GODOY, L.P.; SCHMIDT, A. S.; NETO, A. C.; CAMFIELD, C. E. R.; SANT'ANNA, L. C. C. Avaliação do grau de contribuição das normas de garantia da qualidade ISSO-9000 no desempenho de empresas certificadas. Rev. Adm. UFSM, Santa Maria, v. 2, n. 1, p. 4158, 2009.

GORINI, A. P. F. Panorama do setor moveleiro no Brasil, com ênfase na competitividade externa a partir do desenvolvimento da cadeia industrial de produtos sólidos de madeira. Rio de Janeiro: BNDES, 1998.

ICDI. International Council of Societies of Industrial Design. http://www.icsid.org/. Acesso em: setembro de 2012.

JURAN, J. M. Juran planejando para a qualidade. 3 ed. São Paulo: Pioneira, 1995.

MOZOTA, B. B. The four powers of design: a value model in designer management. Design Management Review, v.17, n.2, p.44, 2006.

NASCIMENTO, M. B. do. A incorporação do design por uma indústria moveleira voltada ao segmento popular: um estudo de caso no pólo moveleiro de Arapongas PR. 2001. 100f. Dissertação (Mestrado em Engenharia de Produção) Universidade Federal de Santa Catarina, Florianópolis, 2001.

PERUZZI, J. M. Manual sobre a importância do design no desenvolvimento de produtos. Bento Gonçalves: SENAI, CETEMO, SEBRAE, 1998.

QUADROS, A. C. O design dos móveis de escritório na s médias e pequenas empresas do setor moveleiro da serra gaúcha - um estudo exploratório. 2002. 101f. Dissertação (Mestrado em Administração) - UFRGS, Porto Alegre, 2002.

SANTOS, F. A. dos. O design como diferencial competitivo. Itajaí: Univali, 2000.

QUARANTE, D. Diseño industrial: elementos introductorios. v.1. Barcelona: Ediciones CEAC, 1992.

TUCKMAN, A. Ideology, quality e TQM. In: WILKINSON, A. e WILLMOTT, H. (eds.) Making quality critical: new perspectives on organizational change. - London: Routledge, 1995.

TURCHI, L. M. Qualidade total: afinal, de que estamos falando?. Texto para discussão no. 459 - Instituto de Pesquisa Econômica Aplicada, 1997.

WOLF, B. O design management como fator de sucesso. Florianópolis: ABIPTI, SEBRAE, CNPq, FIESC/IEL, 1998. 